\title{
A construção de outras formas de ver os ouvidores de vozes
}

\author{
The construction of other ways of seeing the voice hearers
}

\author{
La construcción de otras formas de ver a los oyentes de voces \\ Oliveira, Michele Mandagará de ${ }^{1}$; Ferreira, Roberta Zaffalon²; Silveira, Karine Langmantel ${ }^{3}$; \\ Camargo, Paola de Oliveira ${ }^{4}$; Timm, Silvana Fonseca ${ }^{5}$
}

Como citar este artigo: Oliveira MM, Ferreira RZ, Silveira KL, Camargo PO, Timm SF. A construção de outras formas de ver os ouvidores de vozes. J. nurs. health. 2018;8(n.esp.):e188423

Palavras-chave: Saúde mental; Narração; Alucinações; Ouvidores de vozes; Novas abordagens em saúde mental.

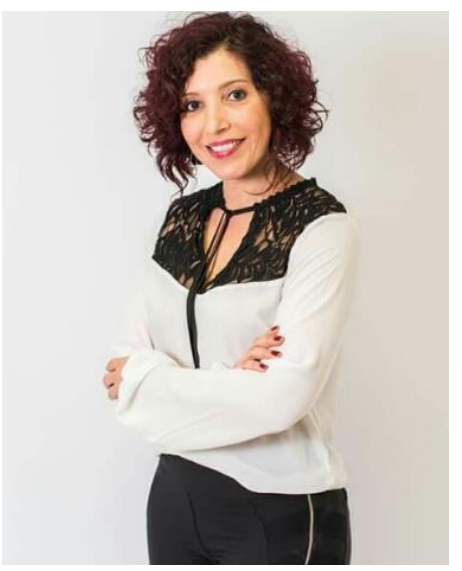

APRESENTAÇÃO

Esta narrativa conta parcialmente a trajetória profissional da psicóloga Octávia Cristina Barros. A entrevista foi realizada durante o I Congresso
Nacional de Ouvidores de Vozes, no Rio de Janeiro - RJ, durante o mês de outubro de 2017, do qual Octávia Cristina Barros era uma das organizadoras. Sua narrativa mostra como enquanto sujeito foi se envolvendo com o tema, a partir do contato com o Instituto de Psiquiatria da Universidade Federal do Rio de Janeiro, do acompanhamento dos grupos de ouvidores de vozes, da trajetória na pós-graduação e na produção do conhecimento. É uma narrativa que retrata como a personagem Octávia é afetada e afeta outas pessoas, despertando o interesse delas sobre a diversidade de experiências daqueles que ouvem vozes.

1 Enfermeira. Doutora em Enfermagem. Universidade Federal de Pelotas (UFPEL). E-mail: mandagara@hotmail.com http://orcid.org/0000-0003-1363-7206

2 Enfermeira. Mestre em Ciências. Universidade Federal de Pelotas (UFPEL). E-mail: betazaffa@gmail.com http: //orcid.org/0000-0002-2521-5652

3 Enfermeira. Mestre em Ciências. Universidade Federal de Pelotas (UFPEL). E-mail: kaa_langmantel@hotmail.com http://orcid.org/0000-0002-2598-5278

4 Pedagoga. Mestre em Ciências. Universidade Federal de Pelotas (UFPEL). E-mail: paolacamargo01@hotmail.com http: / / orcid.org/0000-0002-9169-7602

5 Graduanda em Enfermagem. Universidade Federal de Pelotas (UFPEL). E-mail: silvana_timm@hotmail.com http: / /orcid.org/0000-0001-5486-163X 


\section{NURSING \\ AND

Do manicômio aos ouvidores de vozes

Me chamo Octávia Cristina Barros, tenho 49 anos e sou psicóloga com mestrado em Saúde Mental, realizado pelo Instituto de psiquiatria da Universidade Federal do Rio de Janeiro (IPUB/UFRJ) e sigo minha trajetória profissional e acadêmica nas novas abordagens de saúde mental. As indagações acerca do estigma da loucura já faziam morada em minha mente, desde o tempo em que eu fazia, como psicóloga, intervenções em pessoas com sofrimento psíquico em uma instituição psiquiátrica. Muito me incomodava não obter resultados satisfatórios com as pessoas em tal sofrimento, que a meu ver estavam enredadas em uma cadeia química e muitas vezes, sem oportunidades de expressar seus sentimentos.

Ao trabalhar com saúde mental em um Centro de Atenção Psicossocial, pude perceber que existia outras abordagens que propiciassem ao indivíduo que sofre com transtorno mental, a possibilidade de ser sujeito da sua história, ressignificando-a, bem como retornar ao convívio social sem o estigma de "louco".

Em 2013, no Laboratório de Psicopatologia e Subjetividade do IPUB/UFRJ, coordenado pelo professor Dr. Octavio Domont de Serpa Jr, tive a grande satisfação de ser apresentada a uma nova abordagem para os ouvidores de vozes, termo que se contrapõe à etiqueta diagnóstica da esquizofrenia, oferecida pela psiquiatria tradicional.

Essa nova abordagem consistia numa proposta alternativa de tratamento aos ouvidores de vozes que conheci a partir da leitura do livro 'Na companhia das vozes', de Marius Romme e Sandra Escher. ${ }^{1}$

Eu tive o prazer de conhecer Dr. Marius Romme no IPUB, através da realização do Fórum sobre novas abordagens em saúde mental, organizado pelo Centro Organizacional de Novas Abordagens Terapêuticas (CENAT), na época ele veio ao Brasil para compartilhar abordagens que incentivam as pessoas a lidar com a experiência de ouvir vozes, com a proposta de um saber alternativo, sem os rótulos dos manuais de psiquiatria.

O Marius Romme é um médico fantástico, inovador no campo da saúde mental. Fiquei muito feliz por saber que existiam outras propostas teóricas sobre alucinação auditiva verbal, e então mergulhei nesta temática.

Marius Anton Joannes Romme, é um psiquiatra holandês. Doutor em psiquiatria pela University of Amsterdam. Atualmente é professor visitante no Mental Health Policy Centre, Birmingham City University. É considerado o fundador e principal teórico do Movimento dos ouvidores de vozes. (Notas da Entrevistadora). 


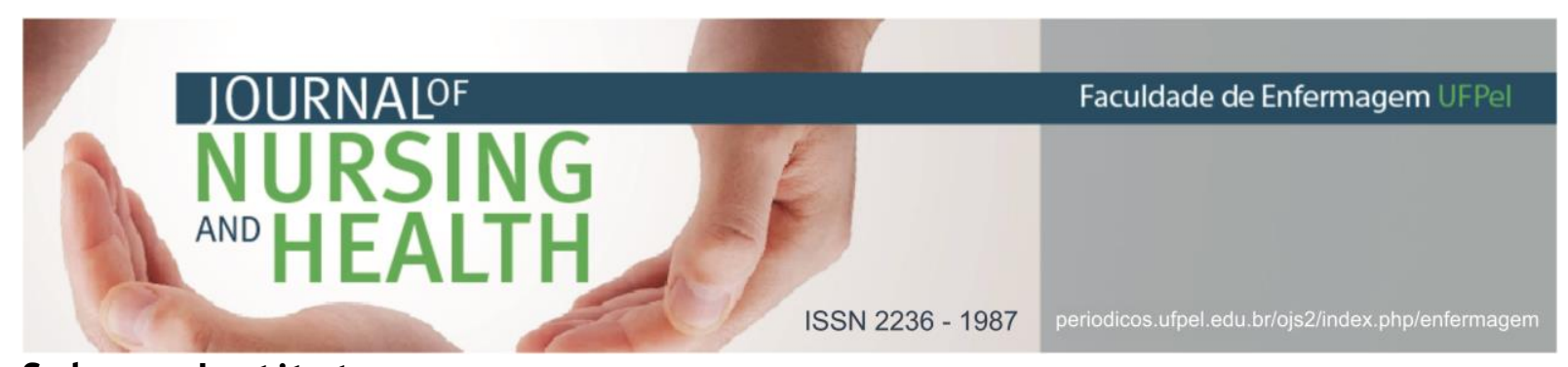

Sobre o Instituto

O Instituto de Psiquiatria da UFRJ foi criado em 1938. É um órgão suplementar do Centro de Ciências da Saúde (CCS), tendo por finalidade desenvolver em nível de excelência, atividades de ensino, pesquisa, extensão e assistência no campo da Psiquiatria e Saúde Mental. Desde sua criação até os dias de hoje o Instituto de Psiquiatria tem marcado sua atuação como uma unidade modelo em pesquisa, ensino de pós-graduação e especialização e como centro gerador de estudos multidisciplinares no campo da Psiquiatria e Saúde Mental. ${ }^{2}$

Octavio Domont de Serpa Júnior é professor da UFRJ, médico, realizou pósdoutorado no Centre de Recherche em Epistémologie Appliquée de l'Ecole Polytechnique - France, Paris. Tem experiência na área de Psicologia, Saúde Mental, Psiquiatria com ênfase em Psicopatologia. (Notas da Entrevistadora).

Me interessei muito sobre este tema, pois como já falei, tive uma trajetória importante de cultura manicomial e isso causava um certo mal-estar, já que as pessoas que escutavam vozes eram sempre vistas como esquizofrênicas, categorizadas no campo da doença, da "patologização". Isso sempre me incomodou, já que estas pessoas eram extremamente medicadas e as narrativas individuais não eram valorizadas.

Para buscar mais informações sobre o assunto, o professor Octavio propôs que eu fizesse uma busca na internet, no site INTERVOICE, com a intenção de realizar uma pesquisa etnográfica, ou seja, observar no ambiente virtual como as pessoas lidavam com o fenômeno "ouvir vozes".

A International Hearing Voices Projects (INTERVOICE) é uma instituição registrada no Reino Unido, que tem por objetivo apoiar o Movimento Internacional dos ouvidores de vozes, conectando as pessoas, compartilhando ideias, distribuindo informações, destacando iniciativas inovadoras, incentivando pesquisa e promovendo seus valores em todo o mundo. ${ }^{3}$

Através do site INTERVOICE, pesquisei outras mídias sociais, como o Facebook. Conheci o Paul Baker que também era moderador do grupo INTERVOICE no Facebook, ao achá-lo, ele prontamente me aceitou na rede social e por ali me deu todas as informações que eu precisava saber, em quantos países existia a rede, onde estava, o que eles faziam e soube também que eles disponibilizavam guias práticos para lidar com as vozes.

Paul Baker tem Pós-graduação em Educação Comunitária é cofundador da Hearing Voices Network na Inglaterra, da Welsh Hearing Voices Network no Reino Unido, da INTERVOICE. Atualmente é secretário da International Mental Health Collaborating Network (IMHCN), rede que vem buscado introduzir uma nova abordagem para ajudar as pessoas em recuperação de problemas de saúde mental (Notas da Entrevistadora). 


\section{JOURNALOF \\ HEALTH \\ ISSN 2236 - 1987}

Com a vinda do Paul Baker para o I Fórum Internacional sobre novas abordagens em saúde mental, o conheci pessoalmente onde conversamos sobre os grupos de ouvidores de vozes. Eu, juntamente com o Abmael de Sousa Alves, o qual já conhecia da época da especialização, tivemos a ideia de reativar o grupo de ouvidores de vozes no IPUB, já que o grupo iniciado pelo professor Octavio havia encerrado as suas atividades. Assim, nós começamos com esta prática que é inovadora e foi um sucesso, pois acredito que é uma nova maneira de lidar com as pessoas que ouvem vozes. Fui totalmente envolvida pelo tema e busquei respostas às indagações antigas, com o alívio de encontrar eco do que acredito: que todas as pessoas vivem experiências diferenciadas, que precisamos ouvi-las e situá-las como sujeitos de direitos em seu contexto histórico cultural.

\section{Manejo das vozes}

A princípio, ouvir vozes pode ser algo impactante, mas existem várias estratégias que apaziguam este sofrimento. Importante salientar que as pessoas têm a ideia de que o uso de medicamentos vai acabar totalmente com a questão de ouvir vozes, mas isso não ocorre assim. Portanto, quando oferecemos para quem ouve vozes a proposta que ela pode ouvir as vozes, que ela pode dialogar com estas vozes e que ela pode conviver com isto, sem dar tanto valor a elas, causa um alívio para a pessoa e até para a família. Estamos trabalhando neste enfrentamento, já que pessoas relatam que por serem ouvidores enfrentam dificuldades até mesmo para conseguir emprego.

A sociedade lida com as pessoas que ouvem vozes de uma forma negativa, preconceituosa, associa o fenômeno ouvir vozes a experiência da loucura, passível de tratamento influenciada por uma prática tradicional, que produz doentes crônicos. Acredito que através das pesquisas que estão sendo realizadas, e os encontros sobre as novas abordagens motivem os profissionais, especificamente os da saúde mental, a buscar formas diferenciadas de intervenção em pessoas que ouvem vozes, e que os mesmos possam conhecer formas alternativas e singulares, inventando novas maneiras de lidar com a questão.

\section{REFERÊNCIAS}

1 Romme M, Escher S. Na companhia das vozes: para uma análise da experiência de ouvir vozes. Lisboa: Editorial Estampa; 1997.

2 Instituto de Psiquiatria da Universidade Federal do Rio de Janeiro (IPUB/UFRJ). História [Internet]. 2018 [acesso em 2018 jun 13]. Disponível em: http://www.ipub.ufrj.br/portal/institucional/historia

3 The international hearing voices network (INTERVOICE). About us [Internet]. 2018 [cited 2018 June 13]. Available from: http://www.intervoiceonline.org/

Data de publicação: 19/09/2018 